\title{
Cartografia do Meio
}

\section{Claudia Zimmer de Cerqueira Cezar*}

\section{Resumo:}

O texto tece considerações acerca do trabalho artístico Cartografia do Meio, que consiste em mapear e depois fotografar lugares cujo nome contém as palavras 'meio' ou 'meia', de modo que estas imagens se apresentem 'meio' visíveis. O apagamento das formas, os contornos diluídos e os meios-tons presentes colaboram com a semi-visibilidade das fotos - que são impressas em papel jornal - produzindo, assim, certa semelhança com a pintura. O fato de fazer o levantamento dos lugares acima citados, bem como de ir a estes locais, percorrer e vivenciar tais paisagens e, também, de produzir um grande número de fotografias deles, delineia um mapa, que é, portanto, entendido como o Mapa do Meio.

\section{Palavras-chave:}

Fotografia; cartografia; meio; semi-visível

Inicialmente pode-se dizer que a Cartografia do Meio, projeto artístico de minha autoria iniciado em 2008, consiste em mapear e depois fotografar lugares cujo nome contém as palavras 'meio' ou 'meia', tentando uma forma de trazer à tona, em imagens fotográficas, características 'meio' visíveis. São paisagens que buscam, de algum modo, mostrar certo vislumbre do 'meio'. Para tanto, as definições de 'meio', como metade ou como ponto central, bem como outros significados pertinentes a tal termo, me permitem tecer certas considerações sobre algumas imagens realizadas no trabalho.

Nestas investigações, surge a fotografia como um 'meio' para capturar, registrar e como forma de pensar as imagens. Aparece ainda o 'meio' como ponto intermediário de tons e formas nas fotos impressas. O papel jornal, então, entra como 'meio' de apresentação e circulação destas fotografias.

Como observei, meu interesse ao iniciar a Cartografia do Meio era realizar imagens em que daria a ver algo 'meio' visível. No período, vinha pesquisando questões relacionadas à semi-visibilidade, à fotografia e à paisagem, sendo esta última investigada a partir de sua percepção e de suas concepções. Concomitantemente a estes fatos, eram recorrentes as indagações a respeito da razão de certos lugares carregarem em seu nome a palavra 'meio' ou 'meia'. Por exemplo: Por que 'Meia Praia', situada em Itapema/SC, tem esta denominação? O que é 'meia praia'? É possível se ter 'metade' de uma praia?

Enfim, estes questionamentos me levaram a realizar um levantamento, via internet, de alguns locais no país - Brasil - com tais palavras em seus nomes, variando

* Mestre em Artes Visuais pela UFRGS e licenciada em Artes Plásticas pela UDESC. 
entre cidades, ruas, rios, praias, lagos e morros. De certa maneira, ao levantar estes pontos geográficos acabei por traçar percursos em um mapa pondo à mostra as proximidades e as distâncias destes lugares (entre si ou do ponto onde me encontro, ou ainda onde o outro se encontra). Curiosamente, grande parte destes lugares situa-se mais à direita de nosso mapa, sendo mais próximos do litoral do que do centro do país (mais perto da borda do que do 'meio').

A partir do levantamento, iniciei um processo de deslocamento visitando Praia do Meio (Florianópolis), Praia do Meio (Torres), Meia Praia (Itapema) e Rio do Meio (Anitápolis). Michel Serres (1998, p.66) pontua que quando nos deslocamos estamos visitando um lugar, pois visitar exige que percebamos durante o movimento, enquanto que ver pressupõe um observador imóvel. Neste sentido, a experiência de transitar, realizar investidas físicas nos locais, percorrer e vivenciar suas paisagens, além de produzir um grande número de fotografias deles, permite-me delinear um mapa, que é então entendido como o 'Mapa do Meio' (Fig. 1). Este, entretanto, não possui uma configuração definitiva, uma vez que ao se explorar novos lugares um outro desenho vai se formando.

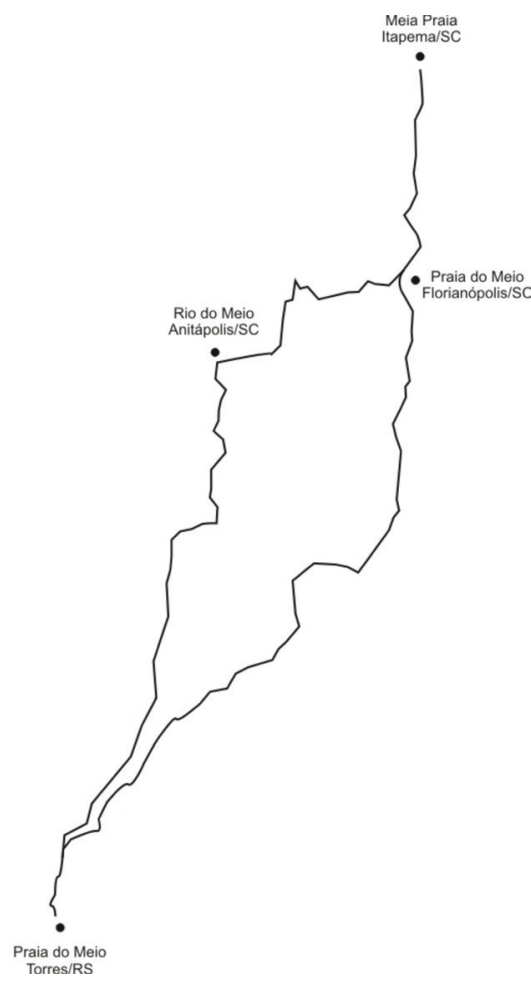

Fig. 1 - Mapa do Meio

Pelo fato de as imagens obtidas advirem de um conjunto de operações, que intitulei Cartografia do Meio, faz-se necessário discorrer, ainda que brevemente, sobre questões pertinentes à cartografia, pois este procedimento possibilitará situar esta produção.

A última década de 60 apresentou no mundo da arte um grande interesse pela cartografia, que aparece conjuntamente à Arte Conceitual, tendo maior difusão entre os artistas da Land Art. Segundo Gilles Tiberghien (2001), o mapa neste período surge como meio de "[...] 'documentar' ações efêmeras ou de localizar realizações de difícil acesso. Ao mesmo tempo também é considerado pelas suas 
características plásticas" (p.49) ${ }^{1}$. Referenciando Lucy Lippard, Tiberghien ainda pontua que o mapa é ao mesmo tempo um lugar, uma viagem e um conceito mental - abstrato e figurativo, remoto e íntimo.

Parece-me que o mapa ocupa uma posição intermediária, pois além de ser um objeto, ele é também uma função e um conceito, sendo a cartografia, então, contribuinte para a exploração de novas possibilidades espaciais.

Em Cartografia sentimental, Suely Rolnik (2006), diferenciando cartografia de mapa, pontua que o mapa é da ordem da macropolítica. É ali que se delineia o encontro dos territórios. A determinação de um mapa exige que se faça a priori o reconhecimento da paisagem. O macro vai englobar o todo, dando uma visão geral, mas também específica. Neste plano, diz a autora, "[...] é que a individuação forma unidades e a multiplicidade, totalizações" (p.60). Ou seja, no trabalho em questão traçou-se um lugar do 'meio', como também 'todos' os lugares do 'meio' que estiveram ao meu alcance.

Para realizar um mapa é preciso que se reconheça o lugar. Neste processo, deslocamento, trânsito e envolvimento são procedimentos comuns do cartógrafo, aquele que vai traçar o mapa. A cartografia é entendida como o ato de construir, conceber, levantar mapas. Cartografar envolve construção, isto é, estruturar/mapear pontos de relevância de um percurso.

Suely Rolnik (2006), que percebe a cartografia como sendo da ordem da micropolítica, sublinha que neste aspecto não há unidades, mas sim singularidades. A cartografia vai se exercendo não somente pelo local mapeado, mas por todos os procedimentos, dados e pontos envolvidos. Nela, não há 'aquele' lugar do 'meio', mas sim 'um' lugar do 'meio', 'um' lugar singular. Em meu trabalho, o 'meio' se repete no nome de cada lugar do mapa traçado, mas cada 'meio' é singular, pois o trânsito de um para o outro traz consigo a diferença. Assim, a Cartografia do Meio é uma tentativa de construção de imagens e de relações que a partir delas vão se tecer, e é também a relação com o lugar.

Diante destas múltiplas entradas e saídas favorecidas pelas linhas traçadas na Cartografia do Meio, iniciou-se um processo de captura das imagens. A fotografia foi o 'meio' definido a priori para registro dos lugares. Mas não só o lugar neste caso foi fator de investigação: também o dispositivo fotográfico. Foram realizadas, então, séries ininterruptas de fotografias. O fotógrafo nunca tira uma única foto - "metralhamos em primeiro lugar, a seleção vem depois" (DUBOIS, 1993, p.162)2. E, neste processo, não poderia deixar de lado o fato de vir pesquisando imagens que se apresentassem semi-visíveis. Foi desta forma que, permitindo um tempo maior de exposição de luz pelo obturador ${ }^{3}$ da câmera, obtive imagens com

\footnotetext{
1 Tradução livre. No original: "[...] "documenter" des actions éphémères ou de localiser des réalisations difficiles d'accès. En même temps on l'a aussi considérée pour ses caractéristiques plastiques".

${ }^{2}$ Cada local visitado me permite obter um número significativo de fotografias; dentre elas também há as que não se destinam à impressão em papel jornal, o que me possibilita realizar novos trabalhos.

${ }^{3}$ O obturador é o que lida com o tempo de incidência da luz no aparelho. É ele que vai fazer o corte a que Philippe Dubois (1993, p. 161) se refere. Observa o autor: "Pode-se dizer que o fotógrafo, no extremo oposto do pintor, trabalha sempre com o cinzel, passando, em cada enfocamento, em cada tomada, em cada disparo, passando o mundo que o cerca pelo fio de sua navalha".
} 
parco limite de contorno.

Percebe-se que, mesmo operando de maneira semelhante, os lugares registrados apresentaram resultados distintos. Vários fatores neste 'meio' podem ser apontados como sendo agentes da diferença: o dia, a hora, a localização, os acidentes, enfim, a geografia de cada local. Todavia, ainda que o registro de cada paisagem se comporte diferentemente, em certos pontos há convergência, uma vez que as fotografias trazem à tona certo apagamento da imagem. É como se algo as segurasse, não as deixando aparecer por completo. Elas são 'meio' visíveis.

No resultado, a materialidade do papel destinado à impressão - neste caso foi escolhido o papel jornal - colaborou para a obtenção de imagens desvanecentes. Tal papel, por suas propriedades favoráveis à absorção de líquido, possibilitou certa diluição das imagens na impressão.

Como o trabalho em questão advém de uma série de regras estipuladas previamente - levantar pontos de relevância em um percurso, visitar estes pontos, fotografar suas paisagens, realizar imagens semi-visíveis, imprimir em papel jornal, deslocar-se novamente -, as descrições a seguir advêm do embate entre minha vivência nos lugares visitados e as imagens resultantes.

Sobre 'Praia do Meio (Florianópolis)' (Fig. 2):

'Praia do Meio' integra o complexo de praias que formam o bairro de Coqueiros, na parte continental de Florianópolis. Dentre as cinco praias que compõem a orla marítima do bairro, 'Praia do Meio' é a terceira, residindo entre quatro praias, duas de um lado e duas de outro. No sentido ilha-continente, a ordem que se estabelece é a seguinte: Praia do Rizzo, Praia da Saudade, Praia do Meio, Praia de Itaguaçu e Praia das Palmeiras (ou Ponta do Bom Abrigo). Sendo um lugar relativamente pequeno, é facilmente alcançado num único golpe de vista à esquerda ou à direita. Nesta proximidade, há um número considerável de dados que possibilitam vários registros. Vegetação, pedras, rancho, mar, areia, pequenos córregos de água e despejos locais constituem a paisagem deste lugar do 'meio'. Entretanto, optei apenas por duas fotografias, das várias realizadas. Fotografias estas que propõem ser completadas pelo olhar, tendo em vista que os elementos que as compõem aparecem pela 'metade'. As figuras vão desaparecendo de forma que, quanto mais distantes os planos, maior fusão com o fundo.
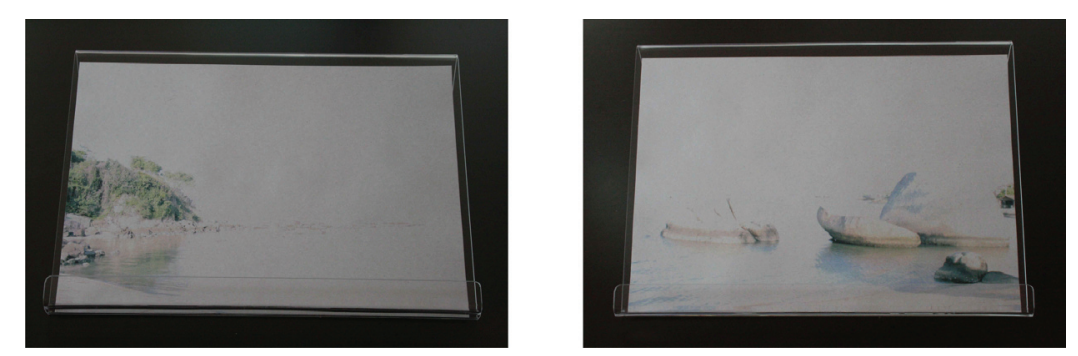

Fig. 2 - Praia do Meio (Florianópolis) Fotografia impressa em papel jornal disposta em display de acrílico $19 \times 28 \mathrm{~cm} \quad 2008$ 
Sobre 'Meia Praia (Itapema)' (Fig. 3):

Opondo-se à 'Praia do Meio (Florianópolis)', 'Meia Praia' apresenta grande extensão. Com aproximadamente 3,5 quilômetros, ocupa um vasto território. Apesar da amplidão, o local quase sem elementos propõe a construção do 'meio' a partir de areia, mar, montanha e céu. Nestas fotografias, a passagem da luz quase sem impedimento pela câmera fotográfica resultou em paisagens formadas por manchas sobre a superfície do papel. Diferentemente das fotografias anteriores, pode-se vislumbrar a linha do horizonte a partir do encontro de campos do papel nu, que sugere o mar, com o esboço de montanhas em tonalidades azuis. A possibilidade do registro das montanhas em cor azulada se deve à perspectiva atmosférica que advém da presença do vapor na atmosfera, manifestando-se num azulamento e na suavização dos contornos das zonas mais distantes da paisagem. Assim, estas imagens se assemelham às aquarelas, mas, em vez de pintadas, são aquarelas fotográficas - umidade do ar que a câmera capturou.
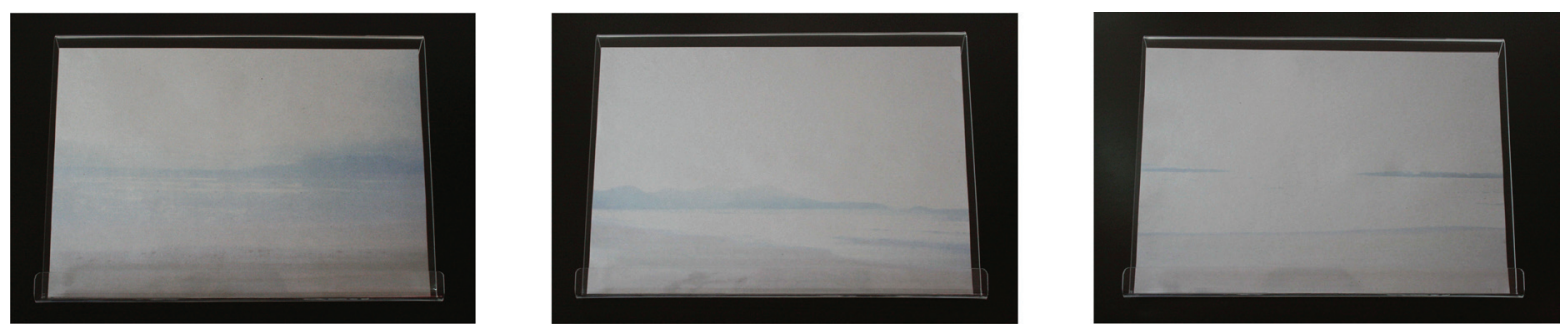

Fig.3 - Meia Praia (Itapema) Fotografia impressa em papel jornal disposta em display de acrílico 19 × 28cm 2008

Outro dia, lendo a dissertação de mestrado de Mariane Rotter (2008) - Meu ponto de vista: o cotidiano e os lugares da imagem -, que discute com minúcia a fotografia, encontrei uma citação de Agnaldo Farias que se refere justamente à questão de imagens que guardam características de pintura. O crítico, remetendo-se ao trabalho de Vera Chaves Barcelos - Cão Veneziano - que consiste em uma foto tremida de um cão deitado em um banco de ônibus, comenta que o borrado dos "[...] contornos do animal e do que está a sua volta, concede-lhes, estranhamente, um aspecto pictórico e retardando, por isso, a temporalidade embutida no fato imediato" (Farias, citado por Rotter, 2008, p.19). Esta pontuação de Farias fez-me perceber a distensão do tempo presente nas minhas próprias fotografias, uma vez que muitas delas, senão todas, parecem pintura. A sensação, inerente à pintura, de que a imagem é construída paulatinamente devido a cada pincelada, dilata o tempo do instante fotográfico. Instante este em que a superfície que recebe a imagem é tingida de uma única vez. Tal paradoxo colabora para que nas imagens por mim realizadas e que são impressas em papel jornal haja uma temporalidade outra que não a imediata da fotografia.

Não à toa as fotos de 'Meia Praia (Itapema)' me evocam algumas aguadas do artista inglês William Turner, que teve uma vasta produção desde o fim do século XVIII até meados do século XIX e desenvolveu suas investigações em torno das 
questões da paisagem e da luz. O artista saía para passeios a pé e também viajava em busca da luz e de conhecer a paisagem. Carregava consigo um caderno em que anotava dados coletados, desenhando cenas percebidas em seu percurso. Para ele, "desenhar [era] parte integrante do curso da jornada, parte do processo de recordação" (BOCKEMÜHL, 2001, p.30). Em seu trânsito, Turner desenvolvia sua cartografia.

Muitas aquarelas de Turner eram realizadas por meio da técnica de 'molhadosobre-molhado', que consiste em trabalhar com a tinta sobre o papel úmido, o que dá a sensação de um ar vaporoso na imagem. Michael Bockemühl (2001) observa que, no lugar de desenhar, o artista começou, em determinado momento, a esboçar fundos coloridos de "molhado-sobre-molhado", para depois acrescentar os pormenores. Em Começo da Cor, de 1819, ele dispõe as cores uma acima da outra, o que sugere a estrutura de uma paisagem. Nota-se que, na aquarela, o branco do papel é utilizado como cor e como luz. Da mesma forma, na impressão em papel jornal, o 'branco' da superfície é usado como cor e como luz.

Sobre 'Praia do Meio (Torres)' (Fig. 4):

Conhecida também como Prainha, a Praia do Meio em Torres tem uma extensão mediana, se comparada à pequenez da Praia do Meio em Florianópolis. Assim como sua homônima catarinense, independentemente do sentido que se segue, ela é a terceira, residindo entre quatro das cinco praias que compõem a orla marítima da cidade. Da esquerda para a direita, a sequência estabelecida é: Praia dos Molhes, Praia Grande, Praia do Meio, Praia da Cal e Praia da Guarita. Deslocandonos pelos 600 metros de sua extensão, podemos encontrar areia, grama e rochas no chão. A brancura da espuma resultante da rebentação das ondas favorece certo contraste com o solo rochoso. A linha do horizonte perfeitamente delineada advém do embate entre o azul do mar e o céu de papel. As imagens resultantes deste lugar transitam entre a fotografia, a aquarela e a pintura em pastel.
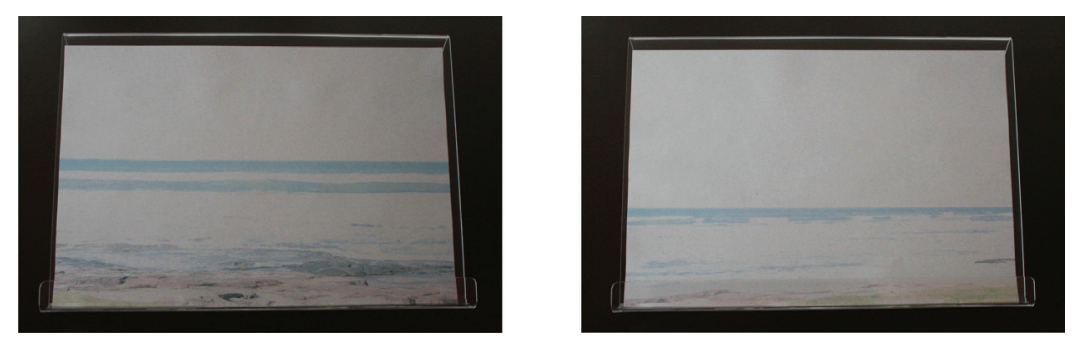

Fig. 4 - Praia do Meio (Torres) Fotografia impressa em papel jornal disposta em display de acrílico $19 \times 28 \mathrm{~cm} \quad 2009$

Sobre 'Rio do Meio (Anitápolis)' (Fig. 5):

Rio do Meio, em Anitápolis, pertence à Grande Florianópolis, distanciando-se 101 quilômetros da capital. No trajeto, não se sabe de seu início, nem de seu fim, tendo sido percorrido somente seu meio. A água segue incessantemente seu curso preenchendo as depressões da terra e deslizando sobre suas elevações. A espuma alva advinda desta tensão vai se desfazendo da brancura à medida que a corre- 
deira perde sua velocidade, formando uma piscina de reflexo azulado. A superfície sem 'pintura' - o rio, que se situa na maioria das imagens mais ao centro -, é ladeada pela vegetação que emoldura o vazio.
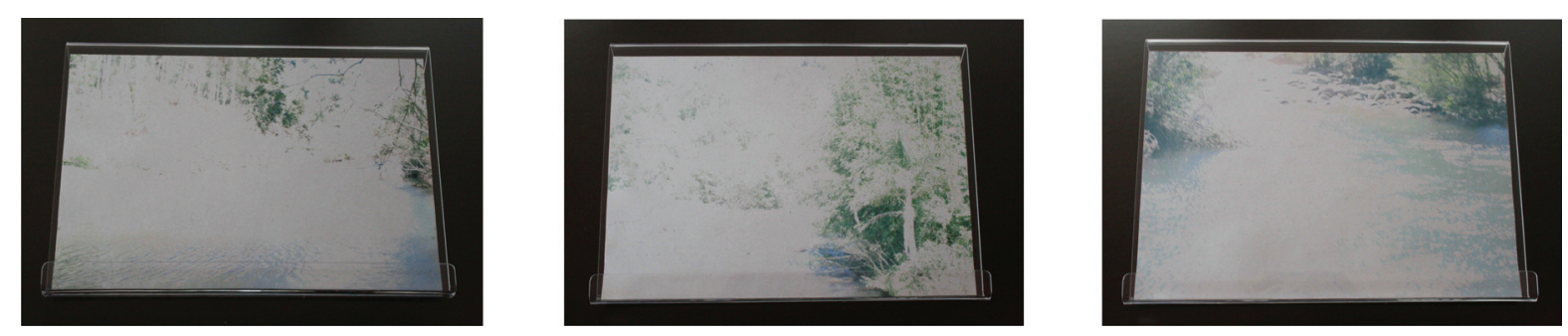

Fig. 5 - Rio do Meio (Anitápolis) Fotografia impressa em papel jornal disposta em display de acrílico $19 \times 28 \mathrm{~cm} \quad 2009$

Mas, voltemos à impressão das imagens, que deixam vir à tona a espessura e materialidade do papel. Espaços em branco, apresentando apenas a cor prévia da superfície, estruturam as paisagens aqui analisadas. Este vazio que possibilita a conformação da imagem é também ponto fundamental na pintura chinesa. Entretanto, para os chineses, a pintura ultrapassa a ordem da estética, tendo base em todo seu sistema de pensamento. Marcada por uma concepção espiritual, a filosofia chinesa presente na pintura também parte da ideia de harmonizar polos, eliminando quaisquer oposições e propondo refletir sobre a relação do homem com o universo.

O artista trabalha com a noção da pincelada única. Neste sentido, a caligrafia foi de suma importância à pintura chinesa, uma vez que, com seu estilo cursivo e rápido, colaborou na pintura com a noção de que a execução de um quadro se faz de maneira espontânea e sem retoques, deixando fluir o ritmo do pintor.

A noção da eliminação de retoque permite uma pequena aproximação, mas também muitos distanciamentos com o corte fotográfico. Em fotografia, uma vez exercido o disparo para a captura da imagem, não é possível um retorno. 0 disparo é único. O obturador da câmera, ao fechar-se, age como uma navalha e toda superfície que recebe a imagem é tingida de uma única vez. Assim, a proximidade à pintura chinesa diz respeito somente à pincelada única, que não permite uma volta para realização de retoques. Entretanto, no que concerne ao processo de cada meio, surgem os afastamentos. Neste sentido, Philippe Dubois (1993, p.197) pontua:

Ali onde o fotógrafo corta, o pintor compõe; ali onde a película fotossensível recebe a imagem (mesmo que seja latente) de uma só vez por toda a superfície e sem que o operador nada possa mudar durante o processo (apenas no tempo da exposição), a tela a ser pintada só pode receber progressivamente a imagem que vem lentamente nela se construir $[\ldots]$.

Na pintura chinesa, determinadas pinceladas são destinadas a modelar, a formar ou fazer surgir o volume dos objetos. Cada pincelada tem seu jogo vazio-cheio. E 
no que diz respeito às formas, a noção 'invisível-visível' é de extrema importância para a pintura paisagista. O artista deve cultivar a arte de não mostrar tudo, manifestada pela pincelada interrompida e também pela "[...] omissão parcial ou total das figuras na paisagem" (CHENG, 1985, p.63).

Diante deste processo, percebe-se a importância do vazio para o aparecimento da imagem. É ele quem vai dar impulso a cada elemento, fazendo emergir suas potencialidades. É assim que, nas fotografias realizadas na Cartografia do Meio, o apagamento de determinadas partes na imagem não somente sugere, mas constrói o que pode ser visto, ou melhor, o que pode ser 'meio' visto.

\title{
Referências:
}

BOCKEMÜHL, Michael. Turner. Lisboa: Taschen, 2001.

CHENG, François. Vacío y plenitud. El lenguaje de la pintura china. Monte Ávila Editores, 1985.

DELEUZE, Gilles. Diferença e repetição. Rio de Janeiro: Graal, 1998.

DUBOIS, Philippe. O ato fotográfico e outros ensaios. Campinas: Papirus, 1993.

ROLNIK, Suely. Cartografia sentimental. Porto Alegre: Sulina, 2006.

ROTTER, Mariane. Meu ponto de vista: o cotidiano e os lugares da imagem. Porto Alegre: UFRGS, 2008. Dissertação de Mestrado.

SERRES, Michel. Atlas. Lisboa: Instituto Piaget, 1998.

TIBERGHIEN, Gilles A. Nature, Art, Paysage. Actes sud / École Nationale Supérieure du Paysage / Centre du Paysage, 2001.

Title:

Cartography of the middle

\begin{abstract}
:
The text deals with the artistic work Cartography of middle that consists in drawing maps and photographing places whose name contains the word 'middle', resulting in images that present themselves as 'semi-visibles'. The effacement of forms, the faded surroundings and the half-tones collaborates with the semivisibility of the photos - printed in newsprint - producing then a certain similiraty with painting. The fact of making the inventary of the places mentioned above, as well as visiting these places, to go throw and experiment these landscapes and to produce a great number of their photographies, draws a map that is understood as the Medium Map.
\end{abstract}

\section{Keywords:}

Photography; cartography; middle; semi-visible 